University of South Florida

DIGITAL COMMONS

Digital Commons @ University of

@ UNIVERSITY OF SOUTH FLORIDA

South Florida

Internal Medicine Faculty Publications

Internal Medicine

$4-1-2011$

\title{
Fish Oil Decreases Inflammation and Reduces Cardiac Remodeling in Rosiglitazone Treated Aging Mice
}

\author{
Ganesh V. Halade \\ University of Texas System, ghalade@usf.edu \\ Paul J. Williams \\ University of Texas System \\ Merry L. Lindsey \\ University of Texas System \\ Gabriel Fernandes \\ University of Texas System
}

Follow this and additional works at: https://digitalcommons.usf.edu/intmed_facpub

\section{Scholar Commons Citation}

Halade, Ganesh V.; Williams, Paul J.; Lindsey, Merry L.; and Fernandes, Gabriel, "Fish Oil Decreases Inflammation and Reduces Cardiac Remodeling in Rosiglitazone Treated Aging Mice" (2011). Internal Medicine Faculty Publications. 71.

https://digitalcommons.usf.edu/intmed_facpub/71

This Article is brought to you for free and open access by the Internal Medicine at Digital Commons @ University of South Florida. It has been accepted for inclusion in Internal Medicine Faculty Publications by an authorized administrator of Digital Commons @ University of South Florida. For more information, please contact digitalcommons@usf.edu. 


\title{
Fish oil decreases inflammation and reduces cardiac remodeling in rosiglitazone treated aging mice
}

\author{
Ganesh V. Halade ${ }^{\mathrm{a},{ }^{,}, \text {Paul J. Williams }}{ }^{\mathrm{a}}$, Merry L. Lindsey ${ }^{\mathrm{b}}$, and Gabriel Fernandes ${ }^{\mathrm{a},{ }^{*}}$ \\ ${ }^{a}$ Division of Clinical Immunology and Rheumatology, Department of Medicine, University of Texas \\ Health Science Center at San Antonio, 7703 Floyd Curl Drive, TX 78229-3900, USA \\ ${ }^{b}$ Division of Cardiology, Department of Medicine, University of Texas Health Science Center at \\ San Antonio, 7703 Floyd Curl Drive, TX 78229-3900, USA
}

\section{Abstract}

Clinical studies suggest that rosiglitazone (RSG) treatment may increase the incidence of heart failure in diabetic patients. In this study, we examined whether a high corn oil diet with RSG treatment in insulin resistant aging mice exerted metabolic and pro-inflammatory effects that stimulate cardiac dysfunction. We also evaluated whether fish oil attenuated these effects. Female C57BL/6J mice (13 months old) were divided into 5 groups: (1) lean control (LC), (2) corn oil, (3) fish oil, (4) corn oil + RSG and (5) fish oil + RSG. Mice fed a corn oil enriched diet and RSG developed hypertrophy of the left ventricle (LV) and decreased fractional shortening, despite a significant increase in total body lean mass. In contrast, LV hypertrophy was prevented in RSG treated mice fed a fish oil enriched diet. Importantly, hyperglycemia was controlled in both RSG groups. Further, fish oil + RSG decreased LV expression of atrial and brain natriuretic peptides, fibronectin and the pro-inflammatory cytokines interleukin- 6 and tumor necrosis factor- $\alpha$, concomitant with increased interleukin-10 and adiponectin levels compared to the corn oil + RSG group. Fish oil + RSG treatment suppressed inflammation, increased serum adiponectin, and improved fractional shortening, attenuating the cardiac remodeling seen in the corn oil + RSG diet fed C57BL/6J insulin resistant aging mice. Our results suggest that RSG treatment has contextdependent effects on cardiac remodeling and serves a negative cardiac role when given with a corn oil enriched diet.

\section{Keywords}

Aging; Corn oil; Fish oil; Cardiac remodeling; Inflammation; Left ventricle hypertrophy; Rosiglitazone

\section{Introduction}

Cardiovascular disease (CVD) is the major cause of death in humans with diabetes. On average, type 2 diabetes lowers life expectancy by 5-10 years [1]. Nearly, 7.8\% (23.6 million) of the US population has type 2 diabetes (T2D) and an additional 57 million people are pre-diabetic [2]. The CVD mortality risk more than doubles in type 2 diabetic patients compared to age-matched controls [3]. The hyperglycemia and hyperlipidemia associated

\footnotetext{
(C) 2011 Published by Elsevier Ltd.

*Corresponding author. Tel.: +1 210567 4679; fax: +1 210567 4592. halade@uthscsa.edu (G.V. Halade), fernandes@uthscsa.edu (G. Fernandes).

Disclosures: None declared.
} 
with T2D exacerbate vascular injury and heart failure [4]. Thiazolidinediones (e.g. rosiglitazone (RSG)) is recommended for the treatment of type 2 diabetes by the American Diabetes Association and the European Association for the Study of Diabetes [5]. RSG, however, also associates with increased incidences of heart failure [6], myocardial infarction (MI), and cardiovascular-related deaths [7,8].

In contrast to clinical trial results, the PPAR $\gamma$ agonist RSG attenuates vascular injury in diabetic animals [9], reducing MI severity and providing a beneficial effect on ischemic cardiomyocytes [10-12]. However, RSG treatment in Sprague-Dawley rats induced eccentric hypertrophy marked by increased expression of atrial natriuretic peptide (ANP) and brain natriuretic peptide (BNP), collagen I and III, and fibronectin [13]. RSG cardioprotective effects have been shown to be critically dependent on high adiponectin levels [14]. Currently, safety issues of RSG for the treatment of T2D are under strict scrutiny and studies that explain the discrepancies in the results are warranted.

Fish oil rich in $\mathrm{n}-3$ polyunsaturated fatty acids, especially eicosapentaenoic acid (EPA; C20:5n-3) and docosahexaenoic acid (DHA; C22:6n-3), has been shown to reduce the incidence of CVD and sudden death [15-17]. Additionally, fish oil protects against inflammation induced bone loss in chronic inflammatory diseases like lupus, rheumatoid arthritis, periodontitis, and osteoporosis [18,19]. The American Heart Association recommends fish oil to reduce CVD [20]. Fish oil supplementation prevents enlargement of the left ventricle (LV) induced by pressure overload [21]. However, whether dietary supplementation of fish oil can improve LV function in obese hyperglycemic mice has not been explored.

In order to address the potential role of fish oil to prevent adverse events associated with RSG, we investigated the dietary effects of fish oil compared to corn oil on RSG-induced $\mathrm{LV}$ remodeling in C57BL/6J aging mice.

\section{Materials and methods}

\subsection{Experimental animals}

Female C57BL/6J mice, weighing approximately $25 \mathrm{~g}$, were purchased from Jackson Laboratories (Bar Harbor, USA). At thirteen months of age, weight matched animals were divided into five groups ( $n=15$ per group) and were maintained in a temperature controlled room $\left(22-25{ }^{\circ} \mathrm{C}, 45 \%\right.$ humidity) on a 12:12-h dark-light cycle. This animal study was approved by the Institutional Laboratory Animal Care and Use Committee of the University of Texas Health Science Center at San Antonio and complies with NIH guidelines. The mice were fed an American Institute of Nutrition (AIN93) diet. Fish oil was obtained from Ocean Nutrition, Canada, and RSG was purchased from Advance Scientific Inc., USA. The mice were fed ad libitum for 5 months. Body weights and food intake of mice were measured weekly.

\subsection{Dietary regime of corn oil and fish oil RSG and fish oil with RSG}

The composition of the semi-purified AIN93 diet is presented in Table 1. The dietary treatment groups were:

1. standard diet fed lean control (LC),

2. $10 \%$ corn oil $(\mathrm{CO})$,

3. $5 \%$ fish oil (30/20, EPA/DHA) with $5 \%$ corn oil (FO),

4. $10 \%$ corn oil with RSG (CO + RSG), and 
5. 5\% fish oil and 5\% corn oil combined with RSG (FO + RSG).

The standard diet for the lean control group was purchased from Harlan, USA (Catalog No. Harlan Teklad LM-485 Mouse/Rat Sterilizable Diet). The uniform calorie containing corn and fish oil enriched experimental diets were produced by an in-house diet preparation facility. RSG was provided in the diet as a $20 \mathrm{mg} / \mathrm{kg} /$ day dose, which is a dose used previously in mice [14,22-24]. Mice were provided with fresh food every day between 1:00 and 2:00 pm. Diets were prepared each week, purged with nitrogen gas, frozen in daily portions and sealed in polyethylene bags to minimize the oxidation of the fatty acids. Uneaten food was weighed and replaced daily to prevent rancidity. To decrease experimental bias, all measurements were performed by an examiner blinded to the experimental diet. All measurements were performed after five months' feeding of the experimental diets.

\subsection{DXA measurement and assessment}

Pre and post diet total body lean masses, abdominal fat mass and hind leg lean mass were measured by Dual energy X-ray absorptiometry, using a Lunar PIXImus mouse bone densitometer (GE, Madison, WI). Data were analyzed with PIXImus software [25,26]. Prior to scanning, mice were anesthetized with an intramuscular injection of $0.1 \mathrm{ml} / 50 \mathrm{~g}$ body weight of Ketamine $\mathrm{HCl} / \mathrm{Xylazine} / \mathrm{Saline}$ (3:2:5, by volume). Total lean mass was obtained for the entire body, excluding the head.

\subsection{Cardiac ultrasound imaging}

Echocardiographic studies were performed using the Vevo $770^{\mathrm{TM}}$ High-Resolution In Vivo Imaging System (Visual Sonics Inc., Canada). All measurements were performed as previously described [27]. Mice were lightly anesthetized with Isoflurane $(0.5-2 \%$ in a $100 \%$ oxygen mix) and two-dimensional targeted M-mode echocardiographic recordings were obtained. Dimensions and wall thickness of the left ventricle (LV) were measured and fractional shortening was calculated.

\subsection{Serum metabolites}

Before sacrifice, mice were fasted for 6-8 $\mathrm{h}$ and blood was withdrawn from the retro-orbital plexus. Fasting glucose (BioAssay Systems, Hayward, CA, USA) nonesterified fatty acid (NEFA) (Wako Chemicals, Richmond, VA, USA) and triglycerides (Cayman Chemical Company, Ann Arbor, MI, USA) were measured in serum using enzymatic spectrophotometric methods. Serum insulin (Cayman Chemical Company, Ann Arbor, MI, USA) and adiponectin (R \& D systems Inc., Minneapolis, MN, USA) were measured by ELISA.

\subsection{Collection and histological analysis of the left ventricle}

Hearts were excised, washed thoroughly with cold PBS and dissected into atria and right and left ventricles, with the LV including the septum. The LV was cut into three transverse sections: apex, middle ring, and base, as previously described [27]. The apex was frozen in liquid nitrogen and used for biological assays. The middle ring was fixed in $10 \%$ formalin for $24 \mathrm{~h}$ at room temperature, processed and embedded in paraffin. Sections $(5 \mu \mathrm{m})$ were stained with hematoxylin and eosin or picrosirius red. Picrosirius red polarization microscopy was performed and birefringence under illumination with polarized light was measured [28]. Quantitative morphometric analysis of collagen content was carried out by light microscopy equipped with digital camera and polarized light (Nikon ECLIPSE TE 2000-TE) interfaced with NIS elements imaging software. At least 3 randomly selected images (20x) of coronary arteries that were $<100 \mu \mathrm{m}$ were analyzed from each LV. 


\subsection{Measurement of pro and anti-inflammatory cytokines in the left ventricle}

Frozen LV apex tissues were pulverized and homogenized at $4{ }^{\circ} \mathrm{C}$ in cold lysis buffer $(20$ mM HEPES, $150 \mathrm{mM} \mathrm{NaCl}, 1 \%$ triton X-100, $10 \%$ glycerol, $1.5 \mathrm{mM} \mathrm{MgCl}_{2}, 1 \mathrm{mM}$ EGTA, $1 \mu \mathrm{g} / \mathrm{ml}$ aprotinin, $1 \mu \mathrm{g} / \mathrm{ml}$ leupeptin, $1 \mathrm{mM}$ PMSF, $100 \mu \mathrm{M}$ ortho vanadate, $\mathrm{pH}$ 7.5) and then centrifuged at $1500 \times g$ for 5 min at $4{ }^{\circ} \mathrm{C}$. The supernatant was collected and the protein content of the samples was measured by the bicinchoninic acid (BCA) protein assay kit (Thermo Scientific, Rockford, IL, USA). LV protein at $25 \mu \mathrm{g}$ was used in each assay and TNF- $\alpha$, IL-6 and IL-10 were measured using ELISA kits (eBiosciences, San Diego, CA, USA).

\subsection{Measurement of total anti-oxidant capacity}

The total antioxidant capacity in $25 \mu \mathrm{g}$ LV protein was measured using a total antioxidant assay kit (Cayman Chemical Company, Ann Arbor, MI, USA) according to the manufacturer's instructions.

\subsection{Left ventricle gene expression using quantitative RT-PCR}

Gene levels for atrial natriuretic peptide (ANP), brain natriuretic peptide (BNP), fibronectin, myosin heavy chain (MHC)- $\alpha$, and MHC- $\beta$ were measured using real time RT-PCR. Frozen LV apex tissue was homogenized in lysis buffer and RNA was isolated using RNeasy Mini kit (Qiagen, Turnberry, Valencia, CA, USA). Total RNA concentration was assessed in the NanoDrop ${ }^{\mathrm{TM}} 1000$ spectrophotometer (Thermo Scientific, USA). Real time RT-PCR was carried out using TaqMan ${ }^{\circledR}$ RNA-to- $\mathrm{C}_{\mathrm{T}}$ 1-step kit (Applied Biosystems, USA) in an ABI Prism 7900HT Sequence Detection System using fluorescent Taq-Man methodology. Real time quantitative PCR was performed for each of the following genes, using ready-to-use primer and probe sets predeveloped by Applied Biosystems (TaqMan Gene Expression Assays) were used to quantify natural natriuretic peptide precursor type a (Nppa, Mm01255748_g1), natural natriuretic peptide precursor type b (Nppb, Mm01255770_g1), fibronectin (Fnl, Mm01256734_ml), MHC- $\alpha$ (Myh6, Mm01313840_01), and MHC- $\beta$ (Myh7b, Mm01249965_01). GAPDH (Gapdh, Mm99999915_g1) was the endogenous control. The results were analyzed with Sequence Detector Software 2.1 (Applied Biosystems). Relative quantification of gene expression was performed using the $2^{-\Delta \Delta \mathrm{Ct}}$ method to calculate fold change.

\subsection{Statistical analysis}

All data are presented as mean \pm SEM. Differences among the groups were assessed by ANOVA followed by Student-Newman-Keuls post test, with the level of significance set at $p<0.05$. Two-way analyses were applied to determine effects of corn oil, fish oil, corn oil + rosiglitazone and fish oil + rosiglitazone, followed by Bonferroni post-tests. Analyses were performed with Graph Pad Prism (La Jolla, USA).

\section{Results}

\subsection{Food intake and body weights}

As shown in Table 1, all groups were provided an equivalent amount of daily calories and the different dietary treatments did not affect the food intake in any group. However, body weight gain was $9.0 \pm 1.0 \mathrm{~g}$ higher in corn oil fed mice compared to a $1.0 \pm 0.5 \mathrm{~g}$ increase in the lean control diet fed mice. This is consistent with the well-characterized diet-induced obesity mouse model [25], in which insulin resistance and T2D phenotype have been studied in detail [29]. The fish oil fed mice showed an intermediate $5.7 \pm 0.5 \mathrm{~g}$ increase in body weight. The corn oil + RSG fed mice showed similar increases in body weight compared to 
fish oil fed mice, which was approximately $5 \mathrm{~g}$ lower than seen in the corn oil fed mice (Table 2).

\subsection{DXA measurement}

As shown in Table 2, corn oil + RSG and fish oil + RSG groups both showed significant increases in total lean mass compared to the corn oil and LC groups. Even though the fish oil and corn oil + RSG fed mice showed a higher total lean mass compared to corn oil and lean controls, a synergistic effect on lean muscle levels was observed in the fish oil + RSG group. In addition, abdominal fat mass was significantly reduced in fish oil + RSG fed mice compared to that of corn oil. Fish oil + RSG did not affect the therapeutic activity of RSG, but decreased abdominal fat mass. Lean control standard diet fed mice showed a minimal fat gain. Furthermore, hind leg lean mass was increased in fish oil + RSG, compared to corn oil + RSG fed mice.

\subsection{Echocardiography measurements - LV mass and contractile function}

After 5 months of dietary intervention, LV hypertrophy was noted only in the corn oil + RSG group compared to the lean control group (Fig. 1A). Dietary supplementation of fish oil + RSG decreased LV mass in corn oil + RSG fed mice. Moreover, fish oil + RSG fed mice showed improved fractional shortening, which was significantly depressed in the corn oil + RSG group compared to all other groups (Fig. 1B).

\subsection{Serum metabolites, pro- and anti-inflammatory cytokines in LV}

Adipokines have been implicated in the pathogenesis of chronic inflammation and insulin resistance associated with obesity [30]. Insulin resistance is strongly associated with obesity, and one mechanism may be the generation of metabolic messengers, such as free fatty acids, by adipose tissue that inhibit insulin action on muscle [31]. Therefore we measured adiponectin and fatty acids levels. As shown in Table 3, adiponectin was significantly increased in corn oil + RSG and fish oil + RSG groups compared to lean control and corn oil fed mice. Triglyceride levels were significantly decreased in fish oil, corn oil + RSG and fish oil + RSG groups compared to that of corn oil fed mice. Furthermore, NEFA levels were significantly decreased in corn oil + RSG and fish oil + RSG compared to that of corn oil fed mice (Table 3). Increased fasting insulin and decreased glucose values in fish oil + RSG and corn oil + RSGfed mice were seen compared to that of corn oil fed mice (Table 3). Interestingly, the addition of RSG with fish oil or corn oil did not alter the pharmacological control of hyperglycemia. This confirms a compatibility of RSG with fish oil or corn oil, and indicates an absence of a diet-drug interaction.

TNF- $\alpha$ and IL-6 have been shown to increase during LV dysfunction [32]. In contrast, increased IL-10 decreases inflammation and decreases LV remodeling [33]. TNF- $\alpha$ and IL-6 concentrations were significantly elevated in corn oil and corn oil + RSG fed mice compared to lean controls. Interestingly, TNF- $\alpha$ and IL-6 levels were also significantly lower in fish oil + RSG fed mice, indicating a supraadditive effect of fish oil + RSG in controlling proinflammatory cytokines. Fish oil + RSG fed mice significantly increased IL-10 concentrations compared to that of corn oil and corn oil + RSG fed mice (Table 3). These results indicate that fish oil reduces pro-inflammatory cytokines (TNF- $\alpha$ and IL-6) and increases anti-inflammatory cytokine (IL-10), which may explain the decreased cardiac remodeling seen in fish oil and fish oil + RSG fed mice.

\subsection{Vascular hypertrophy in LV sections stained with hematoxylin and eosin}

Vessel wall thickness significantly increased in corn oil fed mice compared to lean controls, indicating increased vascular smooth muscle hypertrophy. Increased vascular wall thickness 
was prevented in the fish oil + RSG fed mice, but not in the corn oil + RSG fed mice. Fish oil supplementation with RSG, therefore, can reduce the vascular hypertrophy observed in corn oil fed aging mice (Fig. 2A and B).

\subsection{Fish oil attenuated collagen deposition in LV}

Corn oil and corn oil + RSG fed mice demonstrated increased LV collagen levels compared to lean controls. In contrast, fish oil and fish oil + RSG fed mice showed significantly reduced collagen content and perivascular fibrosis (Fig. 3A and B).

\subsection{Left ventricular gene expression}

The established molecular markers for LV hypertrophy - ANP, BNP and fibronectin - were upregulated in corn oil + RSG fed mice (Fig. 4) [34]. The myosin heavy chain $\beta$ to $\alpha$ ratio, however, was not altered among groups [35]. In contrast, fish oil + RSG treatment decreased ANP, BNP and fibronectin expression. Fish oil supplementation with RSG, therefore, reduces the expression of molecular markers of LV hypertrophy.

In order to explore the specific effects of corn oil, fish oil, corn oil + RSG, fish oil + RSG and diet-drug interactions, two-way ANOVA was applied using Graph Pad prism software. Chronic corn oil diet supplementation resulted in vascular hypertrophy, enhanced collagen deposition and increased glucose levels. Furthermore, mice fed corn oil + RSG developed hypertrophy, reduced fractional shortening and increased ANP, BNP and fibronectin expressions in the LV. Interestingly, fish oil supplementation with RSG prevented the effects observed in corn oil fed mice. The main pharmacological effects of RSG to reduce glucose levels and improve adiponectin levels were not altered by diet treatment.

\section{Discussion}

The primary goal of this study was to evaluate the effect of RSG on parameters of cardiac structure and function, in the setting of diets high in corn oil (n-6 fatty acids) or fish oil (n-3 fatty acids) in an aging mouse model of hyperglycemia and insulin resistance. The novel findings of the present investigation were that corn oil supplementation with RSG resulted in (i) reduced fractional shortening and increased left ventricular and vascular hypertrophy, (ii) increased pro-inflammatory TNF- $\alpha$ and IL- 6 with decreased anti-inflammatory IL-10 in the LV particularly by corn oil and (iii) up-regulation of ANP, BNP and fibronectin expressions. Interestingly, simultaneous supplementation of fish oil with RSG prevented these effects in the obese diabetic mice. Together, our data suggest that RSG provided in a corn oil diet exerts negative effects on $\mathrm{LV}$ remodeling, while fish oil supplementation prevents corn oil + RSG-mediated inflammation and cardiac dysfunction.

$\mathrm{LV}$ remodeling is defined as the structural and functional changes that occur in the LV in response to stress or injury, characterized by an increase in LV mass [36]. Among the molecular pathways involved in LV hypertrophy, myocardial stretch, oxidative stress, and cytokine activation pathways have been the best characterized [37]. Corn oil is primarily composed of linoleic acids (>55\%), and its consumption accounts for $70 \%$ of the dietary polyunsaturated fatty acids consumed. Moreover, corn oil is a significant contributor to the obesity epidemic [38]. We observed increased LV mass in the corn oil + RSG obese aging mice, consistent with a negative impact of corn oil on RSG action. Of note, the dose used in the present investigation was higher than human doses in order to achieve a translational dose in mice $[23,24]$. The increase in LV mass was attenuated when fish oil was added, indicating that fish oil counters the negative effects of the corn oil. As observed in clinical studies that RSG administration with fat intake did not alter the systemic bioavailability 
[39], similarly we noticed glucose lowering pharmacological effect in corn oil and fish oil fed mice in the present animal study.

TNF- $\alpha$ and IL-6 increase during heart failure [40], as well as in obese and type 2 diabetic patients [41]. At the same time, IL-10, a pleiotropic anti-inflammatory cytokine that exerts vasculoprotective effects in numerous animal models, decreases [42]. Oxidative stress, which tips the balance between oxygen free radicals and antioxidant defense mechanisms, also increases in heart failure [32]. Antioxidant treatment with catalase, prevents hypertrophy induced by TNF- $\alpha$ [43]. We demonstrated that fish oil + RSG in aging diabetic mice reduced LV hypertrophy, inflammatory levels, and oxidative stress induced by corn oil + RSG.

Adiponectin plasma levels are negatively correlated to LV remodeling [30]. Elevated plasma adiponectin with fish oil supplementation is due to the activation of PPAR- $\alpha$ in adipose tissue [44]. Adiponectin-deficient mice have enhanced LV hypertrophy that can be rescued by adenovirus-mediated delivery of adiponectin [45], and Tao et al. have recently confirmed that adiponectin is indispensable for RSG-mediated cardioprotection in a mouse MI model [14]. The balance between beneficial and detrimental effects of RSG, therefore, is context dependent. Low adiponectin levels associate with high levels of the inflammatory mediators C-reactive protein and IL-6 [46]. In this study, we show increased adiponectin levels in fish oil + RSG treated aging mice that explain the attenuation of LV hypertrophy.

Chronic corn oil (n-6 fatty acids) supplementation results in age-associated obesity, inflammation, and hyperglycemia [25]. Although RSG treatment controlled hyperglycemia and increased lean mass in the corn oil fed mice, corn oil + RSG also up-regulated mRNA expression of hypertrophy genes (ANP, BNP and fibronectin). Similar results have been reported in Sprague-Dawley rats, as RSG treatment induced eccentric LV hypertrophy despite positive effects on serum glucose levels [13]. Genomic analysis of $d b / d b$ mouse hearts demonstrated transcriptional changes with diabetes that were exacerbated by RSG treatment [47]. Also the evidence that, RSG-induced LV hypertrophy is related to volumeoverload due to higher sodium and water retention by the kidney [48]. In contrast, studies in a mouse reperfusion model showed a protective effect of RSG, but this benefit can be explained by the acute treatment timing [49]. Therefore, length of treatment and edema evaluation are important considerations, providing compelling rationale to study further in detail.

Fish oil increases plasma adiponectin levels, suppresses inflammation, and prevents cardiac remodeling and dysfunction in a pressure overload rat model $[21,50]$. Fish oil also lowers triglycerides and plasma free fatty acids that reduce CVD risk, especially in overweight and T2D patients [51]. Kuda et al. recently showed that fish oil + RSG exerted additive effect in the prevention of obesity, adipocyte hypertrophy, low-grade adipose tissue inflammation, dyslipidemia and insulin resistance [52]. RSG also reduced triglycerides in our aging diabetic fish oil fed mice, consistent with previous reports from other groups [53]. In the clinic, elderly patients with T2D receive the same pharmacological therapy as the younger adult cohort [54]. More than $20 \%$ of the population over 65 years old has diabetes [55]. Our studies provide persuasive motivation to study effects of drugs in different age groups of animals to predict usage related safety and toxicity aspects. Therefore, future studies that investigate effects of chronic RSG treatment in aging animals and humans are warranted. In addition, studies that investigate the ability of fish oil supplementation to prevent or limit adverse effects of RSG superimposed on a corn oil diet are needed. Further studies are also warranted to delineate the diverse effects of individual fish oil components, including EPA and DHA, in the RSG-mediated LV hypertrophy that occurs in aging insulin resistant mice. 


\section{Conclusion}

Taken together, our study demonstrates that fish oil supplementation with RSG reduced LV hypertrophy and inflammation and decreased biomarkers of insulin resistance. Our results support the hypothesis that RSG provided in a corn oil diet induces cardiac inflammation and dysfunction, while fish oil supplementation attenuates this effect. In conclusion, supplementation of fish oil in RSG therapy could become an important therapeutic choice to lower the risk of RSG-mediated cardiac dysfunction.

\section{Acknowledgments}

This work was supported by National Institute Health [R01AT004259-01, 1R01AG030161-01A1 to G.F. and R01 HL075360 to M.L.L.]. The authors would like to thank Dr. Rogelio Zamilpa for his help in echocardiography analysis and to Ms. Nishu Kazi for her help in diet preparation, animal feeding and care. We also thank Dr. Alex Bokov (Epidemiology and Biostatistics) for statistical analysis and the NIA Nathan Shock Center for aging research.

\section{References}

1. Donnelly R, Emslie-Smith AM, Gardner ID, Morris AD. Abc of arterial and venous disease: vascular complications of diabetes. BMJ. 2000; 320:1062-1066. [PubMed: 10764371]

2. [accessed 24.05.2010] http://www.Diabetes.Org/diabetes-basics/diabetes-statistics/

3. Laakso M. Cardiovascular disease in type 2 diabetes from population to man to mechanisms: the Kelly west award lecture 2008. Diabetes Care. 2010; 33:442-449. [PubMed: 20103560]

4. Jagasia D, McNulty PH. Diabetes mellitus and heart failure. Congest Heart Fail. 2003; 9:133-139. [quiz 140-131]. [PubMed: 12826771]

5. Nathan DM, Buse JB, Davidson MB, Ferrannini E, Holman RR, Sherwin R, et al. Management of hyperglycaemia in type 2 diabetes mellitus: a consensus algorithm for the initiation and adjustment of therapy. Update regarding the thiazolidinediones. Diabetologia. 2008; 51:8-11. [PubMed: 18026926]

6. Komajda M, McMurray JJ, Beck-Nielsen H, Gomis R, Hanefeld M, Pocock SJ, et al. Heart failure events with rosiglitazone in type 2 diabetes: data from the record clinical trial. Eur Heart J. 2010; 31:824-831. [PubMed: 20118174]

7. Nissen SE, Wolski K. Effect of rosiglitazone on the risk of myocardial infarction and death from cardiovascular causes. N Engl J Med. 2007; 356:2457-2471. [PubMed: 17517853]

8. Singh S, Loke YK, Furberg CD. Long-term risk of cardiovascular events with rosiglitazone: a metaanalysis. JAMA. 2007; 298:1189-1195. [PubMed: 17848653]

9. Li AC, Brown KK, Silvestre MJ, Willson TM, Palinski W, Glass CK. Peroxisome proliferatoractivated receptor gamma ligands inhibit development of atherosclerosis in ldl receptor-deficient mice. J Clin Invest. 2000; 106:523-531. [PubMed: 10953027]

10. Wayman NS, Hattori Y, McDonald MC, Mota-Filipe H, Cuzzocrea S, Pisano B, et al. Ligands of the peroxisome proliferator-activated receptors (ppar-gamma and ppar-alpha) reduce myocardial infarct size. FASEB J. 2002; 16:1027-1040. [PubMed: 12087064]

11. Liu HR, Tao L, Gao E, Lopez BL, Christopher TA, Willette RN, et al. Anti-apoptotic effects of rosiglitazone in hypercholesterolemic rabbits subjected to myocardial ischemia and reperfusion. Cardiovasc Res. 2004; 62:135-144. [PubMed: 15023560]

12. Rennings AJ, Meijer P, van Uden DJ, Tack CJ, Smits P, Boerman OC, et al. Rosiglitazone reduces ischaemia-reperfusion injury in patients with the metabolic syndrome. Eur Heart J. 2010; 31:983. [PubMed: 20022873]

13. Festuccia WT, Laplante M, Brule S, Houde VP, Achouba A, Lachance D, et al. Rosiglitazoneinduced heart remodelling is associated with enhanced turnover of myofibrillar protein and mtor activation. J Mol Cell Cardiol. 2009; 47:85-95. [PubMed: 19397913]

14. Tao L, Wang Y, Gao E, Zhang H, Yuan Y, Lau WB, et al. Adiponectin: an indispensable molecule in rosiglitazone cardioprotection following myocardial infarction. Circ Res. 2009; 106:409-417. [PubMed: 19940263] 
15. Leaf A, Kang JX, Xiao YF. Fish oil fatty acids as cardiovascular drugs. Curr Vasc Pharmacol. 2008; 6:1-12. [PubMed: 18220934]

16. Ruxton CH, Reed SC, Simpson MJ, Millington KJ. The health benefits of omega-3 polyunsaturated fatty acids: a review of the evidence. J Hum Nutr Diet. 2004; 17:449-459. [PubMed: 15357699]

17. Richard D, Bausero P, Schneider C, Visioli F. Polyunsaturated fatty acids and cardiovascular disease. Cell Mol Life Sci. 2009; 66:3277-3288. [PubMed: 19590823]

18. Sun D, Krishnan A, Zaman K, Lawrence R, Bhattacharya A, Fernandes G. Dietary n-3 fatty acids decrease osteoclastogenesis and loss of bone mass in ovariectomized mice. J Bone Miner Res. 2003; 18:1206-1216. [PubMed: 12854830]

19. Halade GV, Rahman MM, Bhattacharya A, Barnes JL, Chandrasekar B, Fernandes G. Docosahexaenoic acid-enriched fish oil attenuates kidney disease and prolongs median and maximal life span of autoimmune lupus-prone mice. J Immunol. 2010; 184:5280-5286. [PubMed: 20368275]

20. Lichtenstein AH, Appel LJ, Brands M, Carnethon M, Daniels S, Franch HA, et al. Diet and lifestyle recommendations revision 2006: a scientific statement from the american heart association nutrition committee. Circulation. 2006; 114:82-96. [PubMed: 16785338]

21. Duda MK, O’Shea KM, Tintinu A, Xu W, Khairallah RJ, Barrows BR, et al. Fish oil but not flaxseed oil, decreases inflammation and prevents pressure overload-induced cardiac dysfunction. Cardiovasc Res. 2009; 81:319-327. [PubMed: 19015135]

22. Lazarenko OP, Rzonca SO, Hogue WR, Swain FL, Suva LJ, Lecka-Czernik B. Rosiglitazone induces decreases in bone mass and strength that are reminiscent of aged bone. Endocrinology. 2007; 148:2669-2680. [PubMed: 17332064]

23. Reagan-Shaw S, Nihal M, Ahmad N. Dose translation from animal to human studies revisited. FASEB J. 2008; 22:659-661. [PubMed: 17942826]

24. Fernandes-Santos C, Carneiro RE, de Souza Mendonca L, Aguila MB, Mandarim-de-Lacerda CA. Pan-ppar agonist beneficial effects in overweight mice fed a high-fat high-sucrose diet. Nutrition. 2009; 25:818-827. [PubMed: 19268533]

25. Halade GV, Rahman MM, Williams PJ, Fernandes G. High fat diet-induced animal model of ageassociated obesity and osteoporosis. J Nutr Biochem. 2010

26. Halade GV, El Jamali A, Williams PJ, Fajardo RJ, Fernandes G. Obesity-mediated inflammatory microenvironment stimulates osteoclastogenesis and bone loss in mice. Exp Gerontol. 2011; 46:43-52. [PubMed: 20923699]

27. Lindsey ML, Goshorn DK, Squires CE, Escobar GP, Hendrick JW, Mingoia JT, et al. Agedependent changes in myocardial matrix metalloproteinase/tissue inhibitor of metalloproteinase profiles and fibroblast function. Cardiovasc Res. 2005; 66:410-419. [PubMed: 15820210]

28. Ducharme A, Frantz S, Aikawa M, Rabkin E, Lindsey M, Rohde LE, et al. Targeted deletion of matrix metalloproteinase-9 attenuates left ventricular enlargement and collagen accumulation after experimental myocardial infarction. J Clin Invest. 2000; 106:55-62. [PubMed: 10880048]

29. Surwit RS, Kuhn CM, Cochrane C, McCubbin JA, Feinglos MN. Diet-induced type ii diabetes in c57bl/6j mice. Diabetes. 1988; 37:1163-1167. [PubMed: 3044882]

30. Rasouli N, Kern PA. Adipocytokines and the metabolic complications of obesity. J Clin Endocrinol Metab. 2008; 93:S64-S73. [PubMed: 18987272]

31. Boden G. Role of fatty acids in the pathogenesis of insulin resistance and NIDDM. Diabetes. 1997; 46:3-10. [PubMed: 8971073]

32. Remme WJ. Pharmacological modulation of cardiovascular remodeling: a guide to heart failure therapy. Cardiovasc Drugs Ther. 2003; 17:349-360. [PubMed: 14618097]

33. Krishnamurthy P, Rajasingh J, Lambers E, Qin G, Losordo DW, Kishore R. IL-10 inhibits inflammation and attenuates left ventricular remodeling after myocardial infarction via activation of stat3 and suppression of hur. Circ Res. 2009; 104:e9-e18. [PubMed: 19096025]

34. Okere IC, Young ME, McElfresh TA, Chess DJ, Sharov VG, Sabbah HN, et al. Low carbohydrate/ high-fat diet attenuates cardiac hypertrophy, remodeling, and altered gene expression in hypertension. Hypertension. 2006; 48:1116-1123. [PubMed: 17060511] 
35. Nakao K, Minobe W, Roden R, Bristow MR, Leinwand LA. Myosin heavy chain gene expression in human heart failure. J Clin Invest. 1997; 100:2362-2370. [PubMed: 9410916]

36. Lakatta EG, Levy D. Arterial and cardiac aging: major shareholders in cardiovascular disease enterprises. Part ii. The aging heart in health: links to heart disease. Circulation. 2003; 107:346354. [PubMed: 12538439]

37. McKinsey TA, Kass DA. Small-molecule therapies for cardiac hypertrophy: moving beneath the cell surface. Nat Rev Drug Discov. 2007; 6:617-635. [PubMed: 17643091]

38. Ailhaud G, Massiera F, Weill P, Legrand P, Alessandri JM, Guesnet P. Temporal changes in dietary fats: role of n-6 polyunsaturated fatty acids in excessive adipose tissue development and relationship to obesity. Prog Lipid Res. 2006; 45:203-236. [PubMed: 16516300]

39. Freed MI, Allen A, Jorkasky DK, DiCicco RA. Systemic exposure to rosiglitazone is unaltered by food. Eur J Clin Pharmacol. 1999; 55:53-56. [PubMed: 10206085]

40. Levine B, Kalman J, Mayer L, Fillit HM, Packer M. Elevated circulating levels of tumor necrosis factor in severe chronic heart failure. N Engl J Med. 1990; 323:236-241. [PubMed: 2195340]

41. Kralisch S, Klein J, Bluher M, Paschke R, Stumvoll M, Fasshauer M. Therapeutic perspectives of adipocytokines. Expert Opin Pharmacother. 2005; 6:863-872. [PubMed: 15952917]

42. Burchfield JS, Iwasaki M, Koyanagi M, Urbich C, Rosenthal N, Zeiher AM, et al. Interleukin-10 from transplanted bone marrow mononuclear cells contributes to cardiac protection after myocardial infarction. Circ Res. 2008; 103:203-211. [PubMed: 18566343]

43. Nakamura K, Fushimi K, Kouchi H, Mihara K, Miyazaki M, Ohe T, et al. Inhibitory effects of antioxidants on neonatal rat cardiac myocyte hypertrophy induced by tumor necrosis factor-alpha and angiotensin ii. Circulation. 1998; 98:794-799. [PubMed: 9727550]

44. Neschen S, Morino K, Rossbacher JC, Pongratz RL, Cline GW, Sono S, et al. Fish oil regulates adiponectin secretion by a peroxisome proliferator-activated receptor-gamma-dependent mechanism in mice. Diabetes. 2006; 55:924-928. [PubMed: 16567512]

45. Shibata R, Ouchi N, Ito M, Kihara S, Shiojima I, Pimentel DR, et al. Adiponectin-mediated modulation of hypertrophic signals in the heart. Nat Med. 2004; 10:1384-1389. [PubMed: 15558058]

46. Engeli S, Feldpausch M, Gorzelniak K, Hartwig F, Heintze U, Janke J, et al. Association between adiponectin and mediators of inflammation in obese women. Diabetes. 2003; 52:942-947. [PubMed: 12663465]

47. Wilson KD, Li Z, Wagner R, Yue P, Tsao P, Nestorova G, et al. Transcriptome alteration in the diabetic heart by rosiglitazone: implications for cardiovascular mortality. PLoS One. 2008; 3:e2609. [PubMed: 18648539]

48. Song J, Knepper MA, Hu X, Verbalis JG, Ecelbarger CA. Rosiglitazone activates renal sodiumand water-reabsorptive pathways and lowers blood pressure in normal rats. J Pharmacol Exp Ther. 2004; 308:426-433. [PubMed: 14593089]

49. Mersmann J, Tran N, Zacharowski PA, Grotemeyer D, Zacharowski K. Rosiglitazone is cardioprotective in a murine model of myocardial i/r. Shock. 2008; 30:64-68. [PubMed: 18562925]

50. Shah KB, Duda MK, O’Shea KM, Sparagna GC, Chess DJ, Khairallah RJ, et al. The cardioprotective effects of fish oil during pressure overload are blocked by high fat intake: role of cardiac phospholipid remodeling. Hypertension. 2009; 54:605-611. [PubMed: 19597033]

51. Bays HE, Tighe AP, Sadovsky R, Davidson MH. Prescription omega-3 fatty acids and their lipid effects: physiologic mechanisms of action and clinical implications. Expert Rev Cardiovasc Ther. 2008; 6:391-409. [PubMed: 18327998]

52. Kuda O, Jelenik T, Jilkova Z, Flachs P, Rossmeisl M, Hensler M, et al. N-3 fatty acids and rosiglitazone improve insulin sensitivity through additive stimulatory effects on muscle glycogen synthesis in mice fed a high-fat diet. Diabetologia. 2009; 52:941-951. [PubMed: 19277604]

53. Johnson JA, Trasino SE, Ferrante AW Jr, Vasselli JR. Prolonged decrease of adipocyte size after rosiglitazone treatment in high- and low-fat-fed rats. Obesity (Silver Spring). 2007; 15:2653-2663. [PubMed: 18070756]

54. Neumiller JJ, Setter SM. Pharmacologic management of the older patient with type 2 diabetes mellitus. Am J Geriatr Pharmacother. 2009; 7:324-342. [PubMed: 20129254] 
55. Viljoen A, Sinclair A. Safety and efficacy of rosiglitazone in the elderly diabetic patient. Vasc Health Risk Manage. 2009; 5:389-395. 

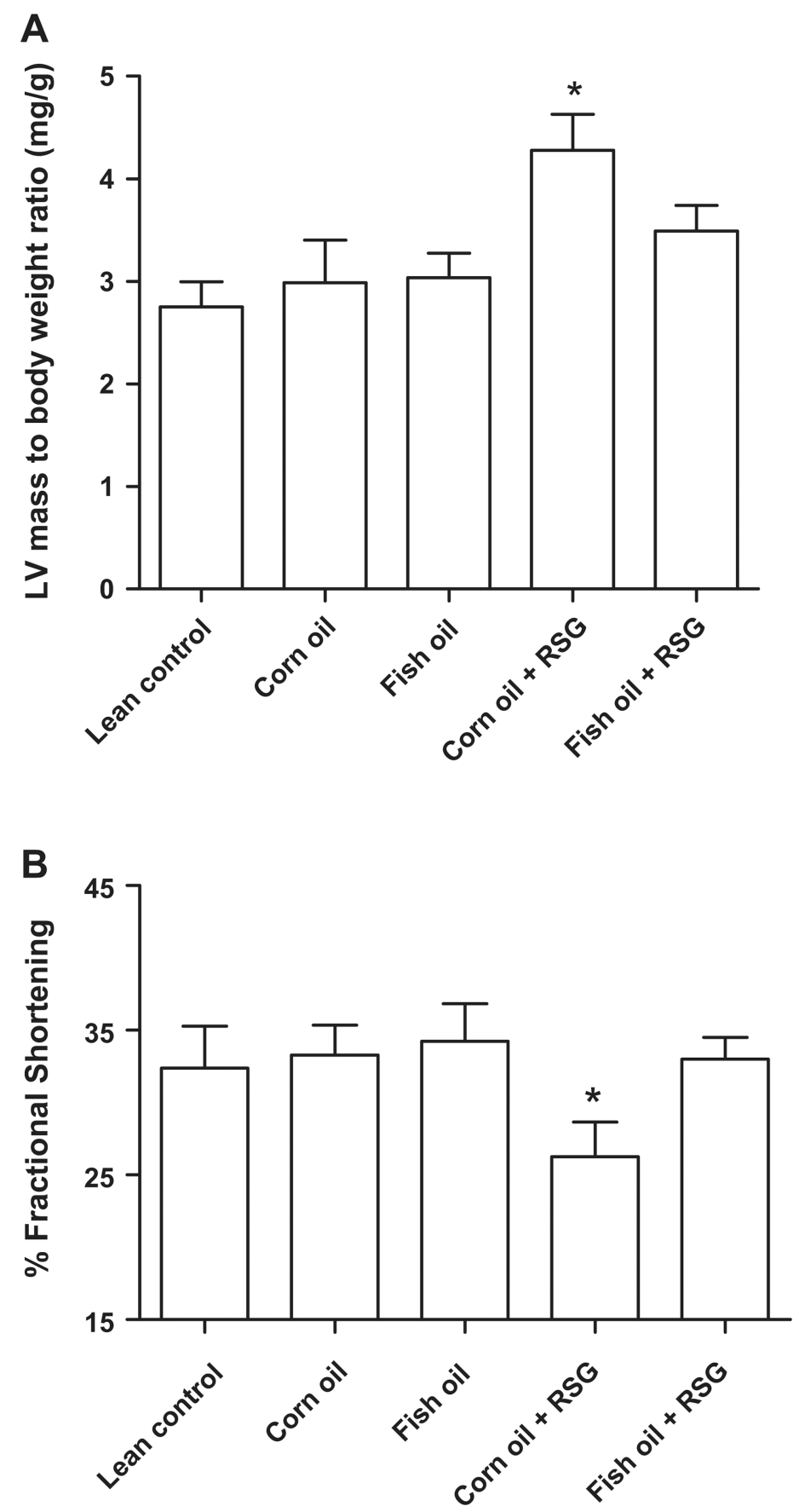

Fig. 1.

Corn oil and RSG, but not fish oil + RSG, increases LV mass to body weight ratio and decreases fractional shortening. C57BL/6J mice were supplemented at 13 months of age with corn oil and fish oil with and without RSG for five months. (A) Left ventricle (LV)/ body weight $(\mathrm{mg} / \mathrm{g})$ ratio and (B) \% fractional shortening at 18 months of age. Data are mean $\pm \operatorname{SEM}(n=5 /$ group). $* p<0.05$ versus lean control. 
A

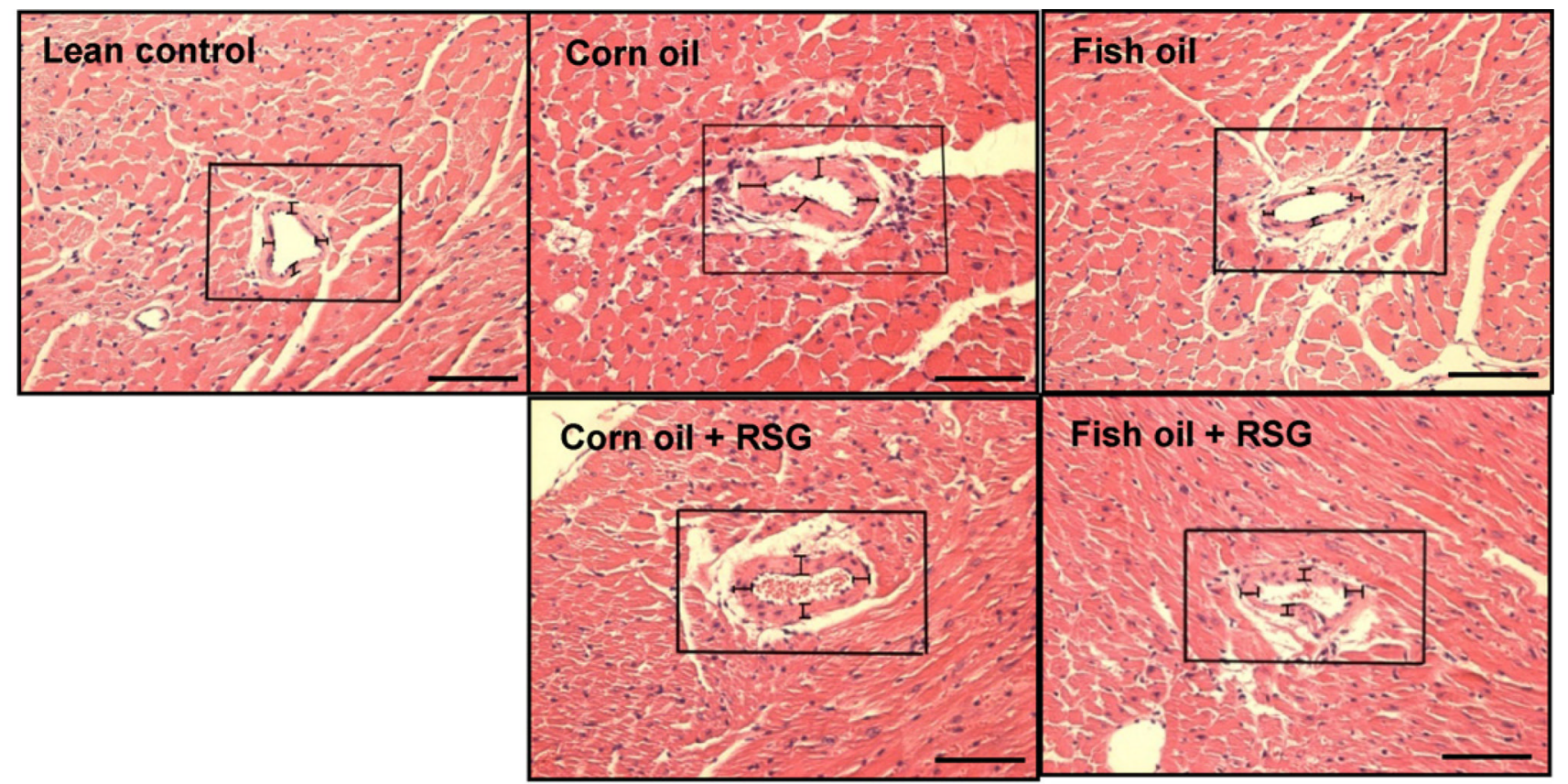

B

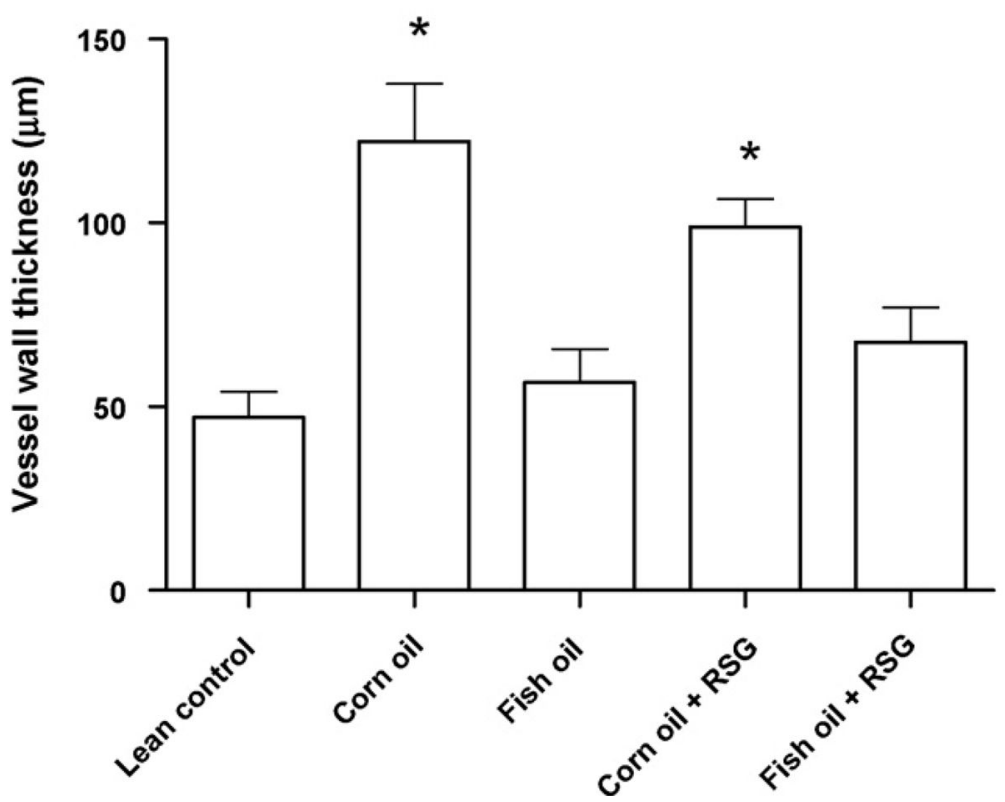

Fig. 2.

Corn oil but not fish oil increases vascular hypertrophy in the absence or presence of RSG. C57BL/6J mice were supplemented at 13 months of age with corn oil or fish oil with and without RSG for five months. Significant vascular hypertrophy was observed in corn oil and corn oil + RSG fed mice compared to lean control. This increase was prevented in the fish oil and fish oil + RSG fed mice. (A) Representative photomicrographs (magnification 20x). (B) Vascular hypertrophy quantification by measuring the vessel wall thickness at 4 random areas. Data are mean \pm SEM ( $n=5$ mice/group). * $p<0.05$ versus lean control. Scale bar in (A) is $150 \mu \mathrm{m}$. 
A

Lean control

Corn oil

Fish oil

Fish oil + RSG

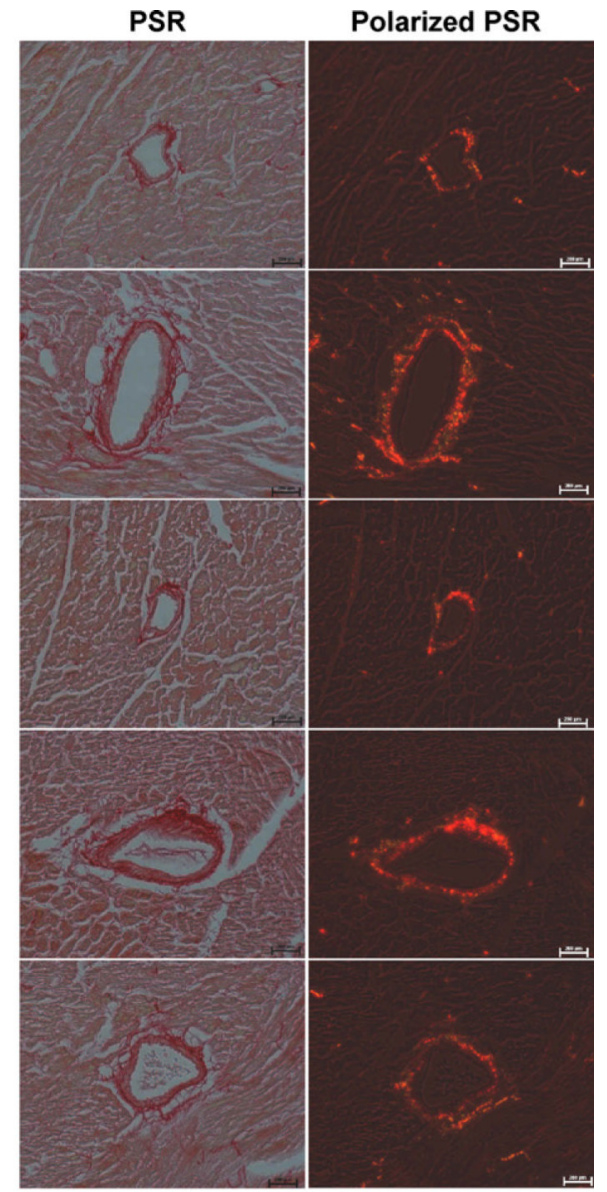

B

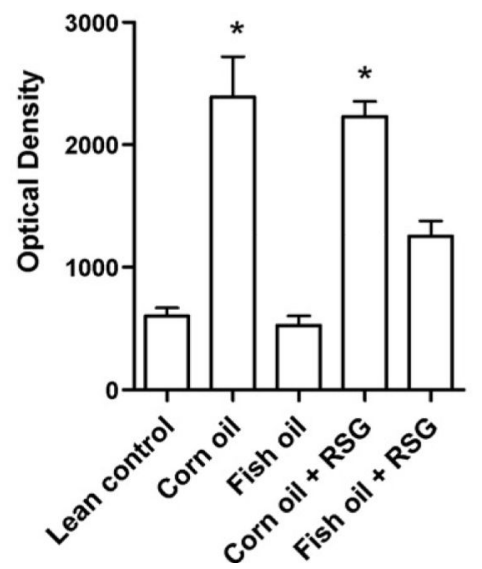

Fig. 3.

Corn oil but not fish oil increases collagen in the left ventricle in the absence or presence of RSG. C57BL/6J mice were supplemented at 13 months of age with corn oil or fish oil with and without RSG for five months. (A) Picrosirius red-stained specimen from mice LV under bright field (left) and under polarized light (right). (B) Collagen brightness measured by Nikon ECLIPSE TE 2000-TE interfaced with NIS elements imaging software. Data are mean $\pm \operatorname{SEM}$ ( $n=4$ mice/group). ${ }^{*} p<0.05$ lean control. Scale bar in $(\mathrm{A})$ is $200 \mu \mathrm{m}$. 

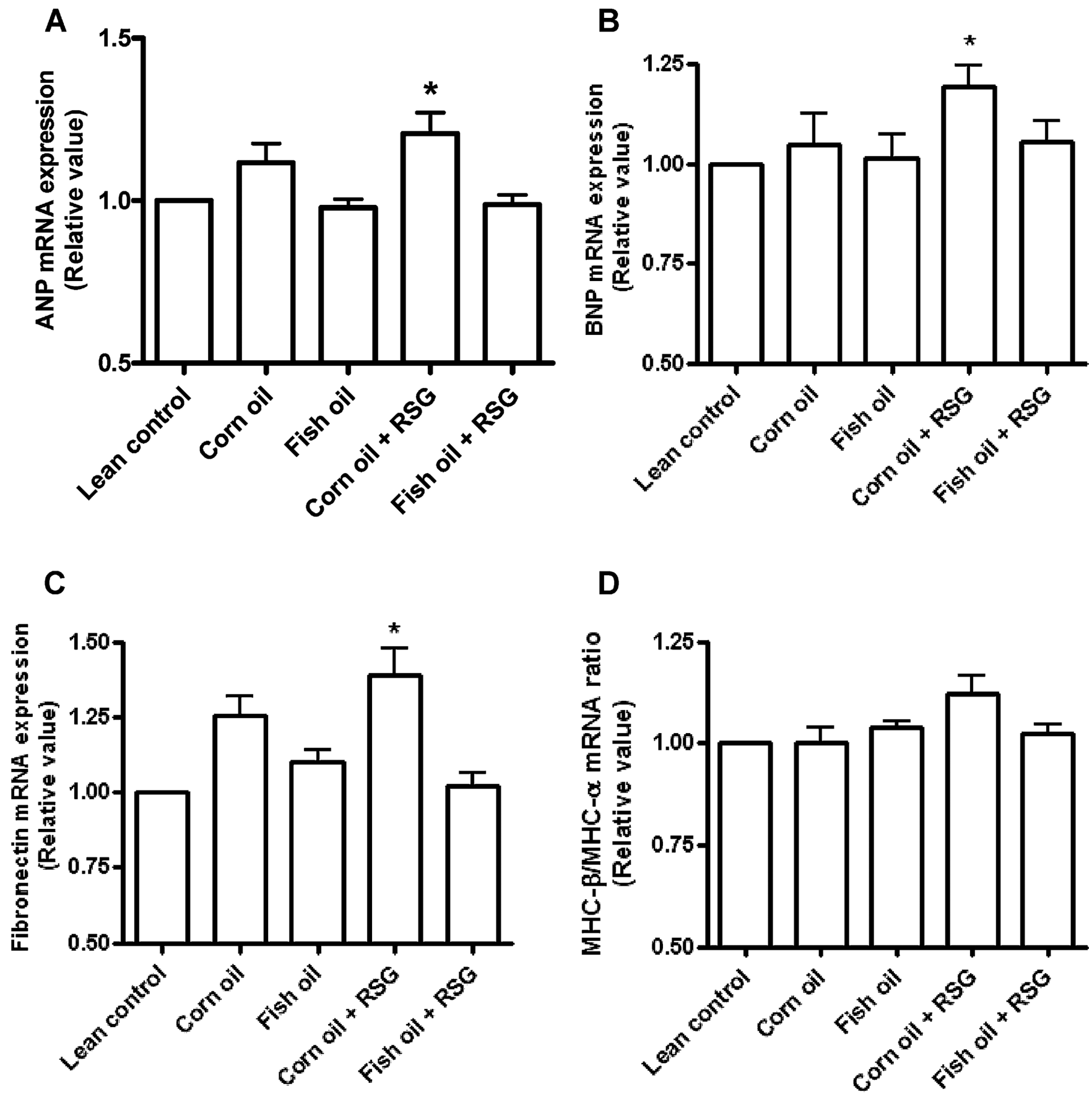

Fig. 4.

Corn oil and RSG, but not fish oil + RSG, increases LV mRNA expression of atrial natriuretic peptide (ANP), brain natriuretic peptide (BNP) and fibronectin. mRNA expression of (A) ANP, (B) BNP, and (C) fibronectin was measured using quantitative realtime PCR in apex of LV of C57BL/6J mice that were supplemented at 13 months of age with corn oil and fish oil with and without RSG for five months. Data are mean $\pm \operatorname{SEM}(n=$ $5 /$ group). ${ }^{*} p<0.05$ versus lean control. 


\section{Table 1}

Composition of semi-purified corn oil or fish oil diets with and without rosiglitazone (RSG).

\begin{tabular}{lllrr}
\hline Ingredient $^{a}(\mathbf{g} / \mathbf{1 0 0}$ g) & $\begin{array}{l}\text { Corn } \\
\text { oil }\end{array}$ & $\begin{array}{l}\text { Fish } \\
\text { oil }\end{array}$ & $\begin{array}{r}\text { Corn } \\
\text { oil + RSG }\end{array}$ & $\begin{array}{r}\text { Fish } \\
\text { oil + RSG }\end{array}$ \\
\hline Casein & 14.00 & & & \\
Corn starch & 42.43 & & & \\
Dextronized corn starch & 14.50 & & & \\
Sucrose & 9.00 & & & \\
Cellulose & 5.00 & & & \\
AIN-93 mineral mix & 3.50 & & & \\
AIN-93 vitamin mix & 1.00 & & & \\
1-Cystine & 0.18 & & & \\
Choline bitartrate & 0.25 & & & \\
TBHQ & 0.10 & & & \\
Vitamin E & 0.04 & & & \\
Corn oil & 10 & 5 & 10 & \\
Fish oil ${ }^{b}$ & 0 & 5 & & \\
Rosiglitazone ${ }^{c}(\mathrm{mg})$ & 0 & 0 & & \\
\hline
\end{tabular}

TBHQ, tertiary butylhydroquinone. A standard diet group was maintained as a lean control.

${ }^{a}$ All diet ingredients were purchased from MP Biomedicals (Irvine, CA, USA).

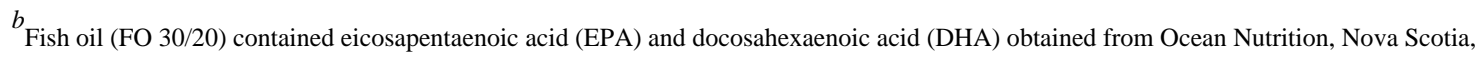
Canada.

${ }^{c}$ RSG was purchased from Advance Scientific Inc., LA, USA. 


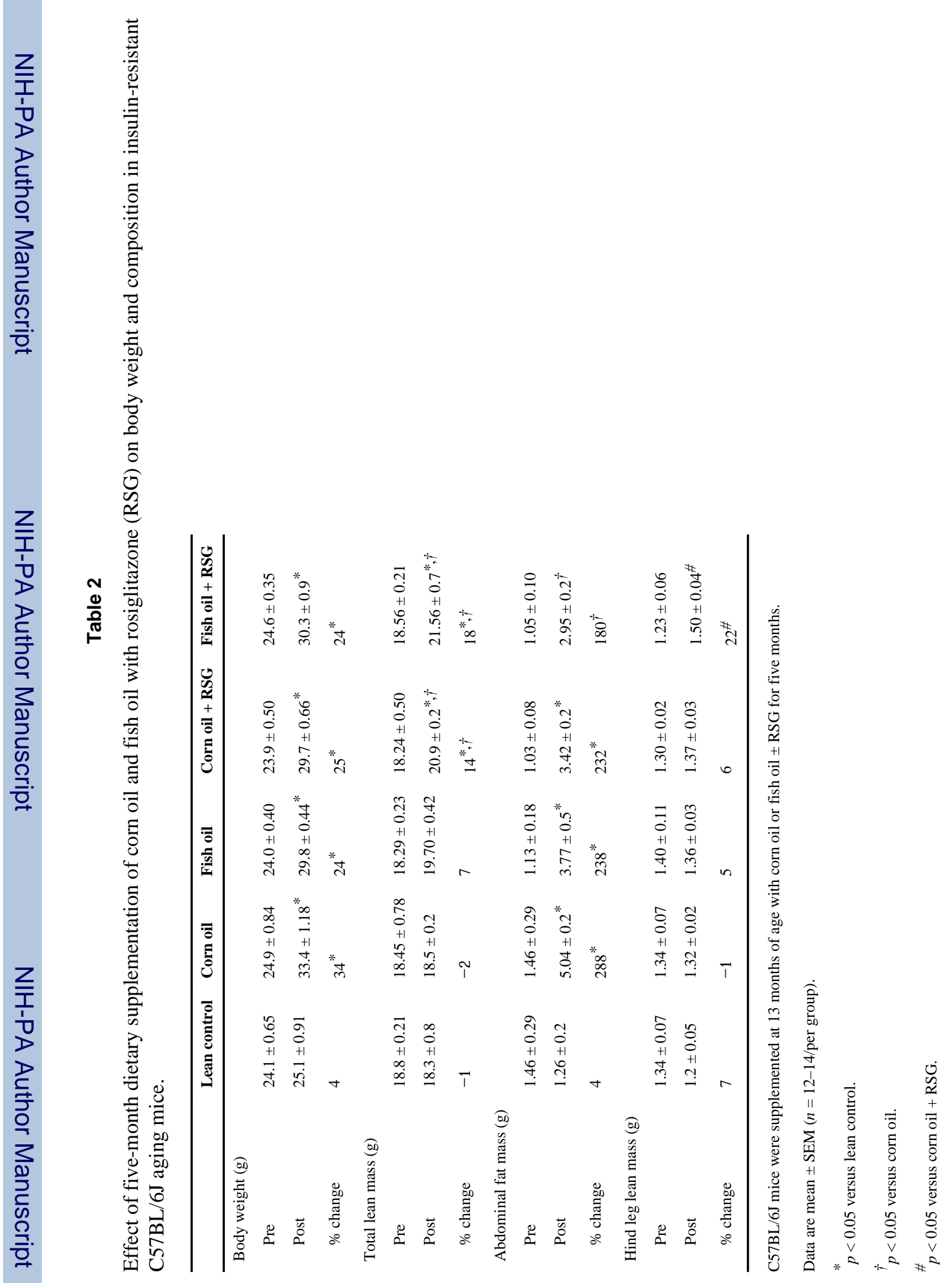




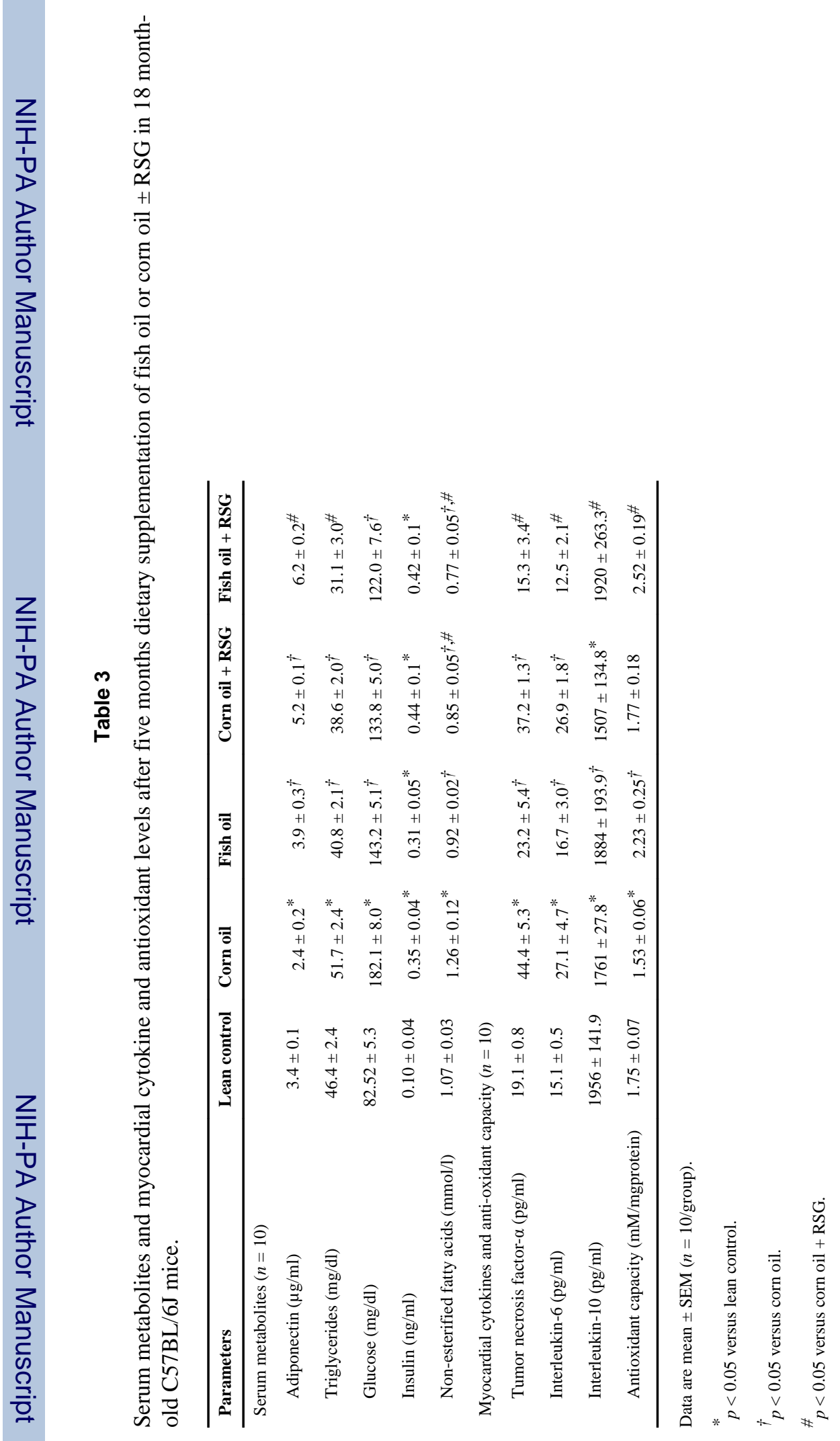

Pharmacol Res. Author manuscript; available in PMC 2012 April 16. 